\title{
Evaluating Isolate Aggressiveness and Host Resistance from Peanut Leaflet Inoculations with Sclerotinia minor
}

\author{
J. E. Hollowell and B. B. Shew, Department of Plant Pathology, and T. G. Isleib, Department of Crop Science, \\ North Carolina State University, Raleigh 27695
}

\begin{abstract}
Hollowell, J. E., Shew, B. B., and Isleib, T. G. 2003. Evaluating isolate aggressiveness and host resistance from peanut leaflet inoculations with Sclerotinia minor. Plant Dis. 87:402-406.

Sclerotinia minor is a major pathogen of peanut in North Carolina, Virginia, Oklahoma, and Texas. Partial resistance to $S$. minor has been reported based on field screening, but field performance is not always correlated with laboratory or greenhouse evaluations of resistance. More efficient screening methods and better understanding of the mechanisms contributing to Sclerotinia blight resistance are needed, and a detached leaf assay was developed and evaluated. Detached leaflets of 12 greenhouse-grown peanut lines were inoculated on the adaxial surface with a 4-mm-diameter mycelial plug of a single isolate of $S$. minor. Leaflets were incubated in the dark at $20^{\circ} \mathrm{C}$ in Nalgene utility boxes containing moistened sand. Lesion length 3 days after inoculation ranged from 11 to $24 \mathrm{~mm}$, with a mean of $19 \mathrm{~mm}$. Lengths differed significantly among the entries, with GP-NC WS 12, an advanced breeding line derived from a cross of NC 6 $\times(\mathrm{NC} 3033 \times$ GP-NC WS 1), being the most resistant. Forty-eight isolates of $S$. minor obtained from peanut were inoculated on leaflets of the susceptible cultivar NC 7 and aggressiveness was assessed by measuring lesion-length expansion. Three days after inoculation, lesion length differed among the isolates and ranged from 2 to $24 \mathrm{~mm}$, with a mean of $15 \mathrm{~mm}$. Finally, the potential for specific interactions between peanut lines and $S$. minor isolates was evaluated. A subset of $S$. minor isolates was selected to represent the observed range of aggressiveness and a subset of peanut entries was selected to represent the range of resistance or susceptibility. Nineweek-old greenhouse- or field-grown plants were compared for five peanut entries. Main effects of isolates and entries were highly significant, but isolate-entry interactions were not significant. The most resistant peanut entry (GP-NC WS 12) performed consistently with all isolates regardless of plant source.
\end{abstract}

Additional keywords: Arachis hypogaea, groundnut, Sclerotinia blight

Sclerotinia blight of peanut (Arachis hypogaea L.) is caused by the soilborne fungus Sclerotinia minor Jagger. The fungus is increasingly prevalent on peanut grown in the United States and can cause severe economic losses in infested fields $(18,19)$. Under relatively cool, moist conditions, sclerotia of $S$. minor germinate myceliogenically to infect peanut stems, pegs, leaves, and pods (19). Diseased stems are light tan in color and eventually become shredded and decayed. Infections may spread from stem to stem or into the crown, killing the plant. Small irregularshaped sclerotia are produced inside or on the surface of stems or pods and allow the fungus to persist in soil for years. Management practices such as using high-quality, fungicide-treated seed, avoiding high seeding rates, minimizing mechanical injury of vines, avoiding excessive use of chlorotha-

Corresponding author: J. E. Hollowell

E-mail: joyce_hollowell@ncsu.edu

Accepted for publication 11 November 2002.

Publication no. D-2003-0212-01R

(C) 2003 The American Phytopathological Society lonil for leafspot sprays, and planting partially resistant cultivars can reduce losses to Sclerotinia blight, but do not completely control the disease (19). The fungicide fluazinam is highly effective against Sclerotinia blight when used as a protectant, but current labeling and cost restrictions do not allow continuous protection throughout the growing season $(4,14)$. The extreme susceptibility of most virginia-type peanut cultivars also undermines the effectiveness of most disease control efforts.

Some peanut breeding lines appear to exhibit high levels of resistance to Sclerotinia blight in field trials. Previous studies have shown that field resistance to Sclerotinia spp. often is based on avoidance rather than true resistance (4-6). In peanut, this "avoidance-based" resistance is derived from characters that reduce yield potential, such as upright habit, sparse foliage, or low peg numbers (6). However, this resistance may fail when inoculum levels are high or when environmental conditions are highly conducive to disease development. Some plants have true partial resistance to Sclerotinia spp., but the ability to suppress infection and colonization by the pathogen is often difficult to identify and differentiate from avoidance in the field. In addition, research on other crops has shown that isolates of $S$. minor differ in aggressiveness $(11,16,21)$. Differences in isolate aggressiveness, host specificity, or both also could account for inconsistent performance of partially resistant cultivars and breeding lines.

Controlled inoculation techniques are needed to identify and quantify partial resistance to Sclerotinia blight in peanut and to evaluate the variability of the Sclerotinia blight pathogen. Several investigators have inoculated detached peanut stems to evaluate resistance to $S$. minor $(3,5,15)$. Detached stem inoculations, however, can give inconsistent results, and a large number of inoculations can be unsuccessful in some trials. Instances in which no infection develops are especially difficult to interpret, because these may reflect either escapes or host immunity. Furthermore, collecting the large amounts of uniform stem tissue needed to compensate for inherent variability in the inoculation method can be difficult or inconvenient. Leaf inoculation techniques previously were used to evaluate host resistance to $S$. trifoliorum in alfalfa (20), S. sclerotiorum in bean (23) and soybean $(1,13)$, and Rhizoctonia solani in peanut (8). Detached leaf inoculations also have been used to evaluate aggressiveness of $S$. minor isolates on lettuce (16) and isolates of Sclerotinia spp. on giant buttercup (9). The objectives of the current study were to develop a leaf inoculation method for screening peanut for resistance to $S$. minor, evaluate aggressiveness in a large collection of isolates of $S$. minor, and evaluate the potential for isolate specificity on selected peanut lines.

\section{MATERIALS AND METHODS}

Isolate collection. Thirty-two isolates of S. minor were collected from four northeastern North Carolina counties, Virginia, and Oklahoma off widely grown peanut cultivars, including NC 10C, VA-C 92R, NC-V 11, NC 7, and NC 12C, throughout the 1998 growing season (Table 1). Peanut stems with symptoms or signs of colonization by $S$. minor were collected in the field and brought back to the lab for isolation. Stem sections 2 to $3 \mathrm{~cm}$ long were removed and rinsed with tap water, towel dried, and placed on potato dextrose agar (PDA) plates for 2 to 3 days until mycelium was present, at which time hyphae were transferred to fresh plates of PDA. Isolates of $S$. minor were cultured on ster- 
ile oat grains for long-term storage (5). Seventeen additional isolates provided by A. V. Lemay (NC), P. M. Phipps (VA), and H. A. Melouk (OK) also were included in the collection (Table 1).

Breeding line resistance. Field trials were conducted in 1996, 1997, and 1999 at the Umphlett Brothers Farm in Middle Swamp, Gates County, NC and in 1998 at the George Kittrell Farm in Corapeake, Gates County, NC. Trials were planted in fields known to be infested with $S$. minor. Planting dates were 23 May 1996, 19 May 1997, 19 May 1998, and 11 May 1999. Each plot consisted of a single row $3.7 \mathrm{~m}$ in length, with 14 seeds planted at $25-\mathrm{cm}$ spacing. Row spacing was $91 \mathrm{~cm}$. Plant stands were counted 4 to 5 weeks after planting, and plants with symptoms of Sclerotinia blight were counted in September each year. Disease incidence was expressed as the proportion of plants with symptoms. Tests were conducted in incomplete block designs with three or four replicates. Multiple-year analysis was performed on adjusted genotype means from individual tests. In the multiple-year analysis of the unbalanced set of genotype-test means, main effects of years, tests within years, and genotypes were included in the statistical model. Genotype means adjusted to a common year and test effect were estimated and compared using protected $t$ tests.

Table 1. Mean length of lesions on detached leaves of NC 7 from Sclerotinia minor isolates collected from peanut grown in North Carolina counties, Virginia, and Oklahoma

\begin{tabular}{|c|c|c|c|}
\hline Isolate $^{y}$ & Origin & Farm or collector & Lesion length $^{\mathrm{z}}$ \\
\hline 1 & Bertie 1 & Harden & $15.6 \mathrm{~d}-\mathrm{k}$ \\
\hline 2 & Bertie 2 & Lewiston & $19.1 \mathrm{~b}-\mathrm{f}$ \\
\hline 3 & Bertie 3 & Davidson & $17.5 \mathrm{~b}-\mathrm{i}$ \\
\hline 4 & Bertie 4 & Davidson & $20.1 \mathrm{bc}$ \\
\hline 5 & Bertie 5 & Davidson & $17.1 \mathrm{~b}-\mathrm{i}$ \\
\hline 6 & Bertie 7 & Davidson & $17.9 \mathrm{~b}-\mathrm{g}$ \\
\hline 7 & Bertie 8 & Harmon & $17.0 \mathrm{c}-\mathrm{i}$ \\
\hline 8 & Bertie 9 & Spruill & $13.6 \mathrm{i}-\mathrm{m}$ \\
\hline 9 & Bertie 10 & Lewiston & $18.7 \mathrm{~b}-\mathrm{f}$ \\
\hline 10 & Bertie 11 & Lewiston & $18.3 \mathrm{~b}-\mathrm{g}$ \\
\hline 12 & Chowan 3 & Jordan & $21.1 \mathrm{ab}$ \\
\hline$* 13$ & Chowan 4 & Jordan & $24.4 \mathrm{a}$ \\
\hline 14 & Chowan 6 & J. Hollowell & $18.7 \mathrm{~b}-\mathrm{f}$ \\
\hline 15 & Chowan 7 & J. Hollowell & $17.5 \mathrm{~b}-\mathrm{i}$ \\
\hline 16 & Chowan 8 & A. Ward & 8.8 op \\
\hline 17 & Chowan 9 & B. Ward & $15.4 \mathrm{e}-\mathrm{k}$ \\
\hline 18 & Chowan 10 & J. Ward & $17.8 \mathrm{~b}-\mathrm{h}$ \\
\hline 19 & Gates 1 & Lemay & $16.6 \mathrm{c}-\mathrm{j}$ \\
\hline$* 20$ & Gates 3 & Umphlett & $21.1 \mathrm{ab}$ \\
\hline 21 & Gates 4 & Umphlett & $18.8 \mathrm{~b}-\mathrm{f}$ \\
\hline$* 22$ & Gates 5 & Umphlett & $13.8 \mathrm{~h}-\mathrm{m}$ \\
\hline 23 & Gates 6 & Umphlett & $1.7 \mathrm{q}$ \\
\hline$* 24$ & Gates 8 & Umphlett & $1.8 \mathrm{q}$ \\
\hline 25 & Gates 9 & Kitrell & $15.7 \mathrm{~d}-\mathrm{k}$ \\
\hline 26 & Gates 10 & Kitrell & $15.2 \mathrm{f}-\mathrm{k}$ \\
\hline 27 & Gates 11 & Kitrell & $10.81-\mathrm{p}$ \\
\hline 28 & Gates 12 & Kitrell & $15.7 \mathrm{~d}-\mathrm{k}$ \\
\hline 29 & Gates 13 & Umphlett & $19.3 \mathrm{~b}-\mathrm{e}$ \\
\hline 30 & Perquimans 1 & Elliott & $16.5 \mathrm{c}-\mathrm{j}$ \\
\hline 31 & Perquimans 2 & Madre & $19.4 \mathrm{bcd}$ \\
\hline 33 & Perquimans 6 & R. Hollowell & $7.7 \mathrm{p}$ \\
\hline 34 & Perquimans 7 & Baker & $15.6 \mathrm{~d}-\mathrm{k}$ \\
\hline 35 & Perquimans 11 & R. Hollowell & $19.2 \mathrm{~b}-\mathrm{f}$ \\
\hline 36 & Virginia 1 & Mozingo & $10.3 \mathrm{~m}-\mathrm{p}$ \\
\hline 37 & Virginia 2 & Mozingo & $11.9 \mathrm{k}-\mathrm{o}$ \\
\hline 38 & Virginia 3 & Phipps & $1.5 \mathrm{q}$ \\
\hline 39 & Virginia 4 & Phipps & 9.5 nop \\
\hline 40 & Virginia 5 & Phipps & $16.6 \mathrm{c}-\mathrm{j}$ \\
\hline 41 & Virginia 6 & Phipps & $11.9 \mathrm{k}-\mathrm{o}$ \\
\hline$* 42$ & Virginia 7 & Phipps & $2.9 \mathrm{q}$ \\
\hline 43 & Virginia 8 & Phipps & $14.5 \mathrm{~g}-1$ \\
\hline 44 & Virginia 9 & Phipps & $12.8 \mathrm{j}-\mathrm{n}$ \\
\hline 45 & Virginia 10 & Phipps & $15.6 \mathrm{~d}-\mathrm{k}$ \\
\hline 46 & Virginia 11 & Phipps & $16.6 \mathrm{c}-\mathrm{j}$ \\
\hline 47 & Virginia 12 & Phipps & $15.2 \mathrm{f}-\mathrm{k}$ \\
\hline 48 & Virginia 13 & Phipps & $13.7 \mathrm{i}-\mathrm{m}$ \\
\hline 49 & Oklahoma 2 & Melouk & $14.4 \mathrm{~g}-1$ \\
\hline 50 & Oklahoma 3 & Melouk & $17.9 \mathrm{~b}-\mathrm{g}$ \\
\hline 58 & $12-\mathrm{B}$ & Phipps & $\ldots$ \\
\hline
\end{tabular}

$\mathrm{y} *=$ Selected for isolate-host specificity test.

${ }^{\mathrm{z}}$ Based on mean lesion length in millimeters 3 days after inoculation. Values followed by the same letter are not significantly different according to Waller-Duncan procedure with $K=100$. Minimum significant difference was $4.0 \mathrm{~mm}$.
Based on the results of the field evaluations, nine peanut cultivars and breeding lines were selected for evaluation of resistance by leaflet inoculation. The lines selected represented a range of field resistance and included the cultivars VA 93B, VA 98R, and Perry, which are described as having moderate resistance to Sclerotinia blight $(7,12,17$; Table 2). In addition to these lines, the wild-species-derived lines GP-NC WS 12 and GP-NC WS 15, which were reported to be resistant in previous field trials (14), were tested along with the resistant runner-type cultivar Tamrun 98 (22). Leaflets of the 12 peanut breeding lines and cultivars were inoculated individually to determine their level of resistance to $S$. minor.

In initial screens, detached stems collected from either field- or greenhousegrown plants were inoculated in the greenhouse with oat grains infested with $S$. minor in several experiments $(5,20)$. These inoculations produced inconsistent results; therefore, a leaflet inoculation method was developed. The 12 breeding lines were grown in the greenhouse for 8 weeks before inoculation. The second fully expanded leaf from the apex of the main stem of each plant to be screened was detached with a razor blade. Washed quartz play sand $\left(275 \mathrm{~cm}^{3}\right)$ was added to a 19-by-16by-4-cm Nalgene utility box with a snugfitting lid. Water $(110 \mathrm{ml})$ was added to the sand and the wet sand was distributed evenly across the bottom of the container. A 6-mm mesh wire screen was placed on top of the moistened sand to prevent leaflets from directly contacting the wet sand. Each leaf was separated into four leaflets. Ten leaflets from a single breeding line were arranged in two rows, five leaflets per row, with the adaxial sides facing upward in the utility box.

All leaflets were inoculated with $S$. $m i$ nor isolate 58, which was shown to be aggressive in several previous studies (5). The isolate was grown for 2 days on PDA (16 $\mathrm{ml}$ of agar per 9-cm-diameter petri plate). Plugs $4 \mathrm{~mm}$ in diameter were cut from the actively growing edge of the $S$. minor culture and placed in the center of each leaflet, mycelium-side down. The peanut leaflets were not wounded and were misted with deionized water. A surfactant (30 $\mu \mathrm{l}$ of Tween 20 per $100 \mathrm{ml}$ ) was added to ensure relatively uniform distribution of moisture on the leaflet surfaces. The box was covered with the lid and incubated in the dark at $20^{\circ} \mathrm{C}$. Lesions were measured (lengthwise direction of leaflets) at 48 and $72 \mathrm{~h}$ after inoculation, using $0.254-\mathrm{cm}$ increments. Preliminary studies indicated very high correlations between lesion length, width, and area; therefore, lesion length was used in subsequent experiments. An experimental unit was a box with 10 leaflets of the same line and the experimental design was a randomized complete block with four replicates of each 
line. The experiment was repeated once for a total of two trials.

Isolate aggressiveness. Forty-eight isolates of $S$. minor were screened on the susceptible cultivar $\mathrm{NC} 7$, which is in the pedigree of several of the selected lines. Leaflets from greenhouse-grown peanut plants were used for the inoculations using the same technique as described above. Each isolate was evaluated on a single leaflet per replicate, with isolates randomized within boxes containing 10 leaflets each. The five boxes required to complete a replicate were blocked together in a randomized complete block design with 10 replicates. Lesions were measured after 48 and $72 \mathrm{~h}$.

Isolate-host specificity. Five breeding lines or cultivars representing high (GPNC WS 12), moderate (N92056C and NC 7), or low (N91026E and Perry) resistance to lesion development based on the resistance screening studies described above were used to assess isolate-host specificity. The lines were planted on 17 May 1999 in the greenhouse or on 13 May 1999 in field plots located at Clayton, NC. On 19 July 1999, leaves were collected from both sets of plants. Six $S$. minor isolates were used to inoculate the test lines with the inoculation technique described above. Two aggressive isolates (numbers 13 and 20), one intermediate isolate (number 22), two less aggressive isolates (numbers 24 and 42), and the isolate used in previous years' tests (number 58) were chosen. A split-split plot experimental design was used with isolates as whole plots, source of plant material (greenhouse or field) as subplots, and peanut lines as sub-subplots. There were eight replicate blocks. The entire test was repeated with leaves collected on 26 July 1999.

Data analysis. All data were analyzed with the general linear models procedure (PROC GLM) of SAS (version 8; SAS Institute, Cary, NC). Data from trials of similar experiments were combined and analysis of variance was conducted to identify significant effects of trials, treatments, and interactions. Means were combined across trials when no significant interactions involving trials were found. When significant treatment effects were found in the analysis of variance, means were compared with the Waller-Duncan procedure with $\mathrm{K}=100$, which approximates $\alpha=$ 0.05 . Single degree of freedom contrasts were calculated to compare groups of isolate means.

\section{RESULTS}

Breeding line resistance. Mean incidence of Sclerotinia blight in field trials conducted from 1996 to 1999 ranged from $62.1 \pm 5.4 \%$ on NC 7 to $3.9 \pm 8.1 \%$ on N96076L (Table 2). The cultivars VA 93B, VA 98R, and Perry had intermediate values of mean disease incidence in these experiments.

Results of the analysis of variance of the leaflet inoculation data showed no significant trial effects and combined results are presented. Three days after inoculation, lesion length on the 12 peanut breeding lines ranged from 11 to $24 \mathrm{~mm}$, with a mean of $19 \mathrm{~mm}$ (Table 2). Lesion length differed significantly among the lines, with GP-NC WS 12, a germplasm line derived from an $A$. hypogaea $\times A$. cardenasii cross, being the most resistant. Three lines (N92056C, N96074L, and N96076L), which exhibited low disease incidence in the field evaluations, had relatively small lesions in the leaflet inoculations. Lesion length on NC 7 was $18 \mathrm{~mm}$, which was intermediate among the lines tested. The longest lesions were produced on cvs. Perry, Tamrun 98, and VA 98R. A simple correlation coefficient of $0.573(P=0.107$, $n=9$ ) was calculated for the relationship between mean disease incidence in the field and lesion length on inoculated detached leaves. Based on these results and the field performance data (Table 2), lines were selected to represent low (Perry and N91026E), moderate (NC 7 and N92056C), and high (GP-NC WS 12) levels of resistance in the isolate-host specificity experiment.

Isolate aggressiveness. Results of the analysis of variance of lesion lengths of 48 $S$. minor isolates showed no significant trial effects and combined results are presented. Isolates varied significantly in aggressiveness (Table 1). Lesion length 3 days after inoculation ranged from 2 to 24 $\mathrm{mm}$, with a mean of $15 \mathrm{~mm}$. Lesion length for most isolates fell in the range of $>15$ to $18 \mathrm{~mm}$ (Fig. 1). Isolates 20 and 13 were selected as aggressive, isolates 42 and 24 as less aggressive, and isolate 22 to represent average aggressiveness in the isolatehost specificity tests. Based on contrasts, average lesion length produced by isolates from Gates County $(13.7 \mathrm{~mm})$ was smaller $(P<0.0001)$ than the mean for all other counties in North Carolina $(17.1 \mathrm{~mm})$. No other effects of region, county, or farm within county on mean isolate aggressiveness were found.

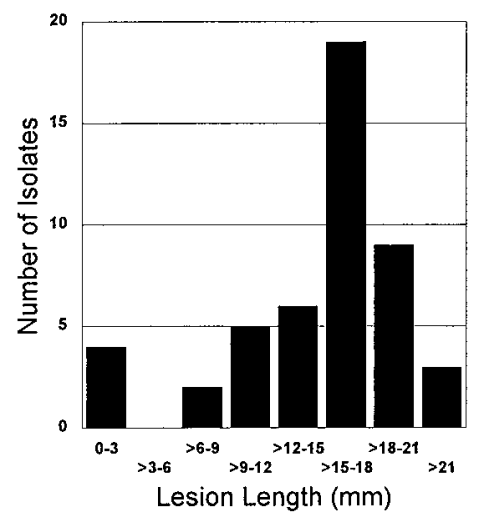

Fig. 1. Frequency distribution of mean lesion lengths produced by 48 Sclerotinia minor isolates on detached leaves of peanut cultivar NC 7.

Table 2. Peanut breeding lines and their reactions in field trials and detached leaf assays to Sclerotinia minor ${ }^{\text {u }}$

\begin{tabular}{|c|c|c|c|c|c|}
\hline \multirow[b]{2}{*}{ Entry $^{v}$} & \multirow[b]{2}{*}{ Parentage } & \multicolumn{3}{|c|}{ Field rating } & \multirow[b]{2}{*}{ Mean lesion length ${ }^{y}$} \\
\hline & & Proportion ${ }^{w}$ & SE & $N^{\mathrm{x}}$ & \\
\hline *Perry & [NC $7 \times$ Florigiant, $($ F2-08-B-B-A03:F07)] $\times$ N90021 & 0.425 & 0.063 & 6 & 24.4 ay \\
\hline VA 98R & VA $81 B \times$ VA 78039 & 0.426 & 0.113 & 2 & $22.7 \mathrm{ab}$ \\
\hline Tamrun $98^{z}$ & TP $107-11 \times($ TXAG- $5 \times$ TP $107-11)$ & & & $\ldots$ & $22.7 \mathrm{ab}$ \\
\hline *N91026E & $\mathrm{NC} 7 \times \mathrm{NC} 9$ & 0.533 & 0.091 & 4 & $21.9 \mathrm{~b}$ \\
\hline GP-NC WS $15^{z}$ & NC $6 \times(\mathrm{PI} 270806 \times$ GP-NC WS 4) & & $\ldots$ & $\ldots$ & $21.3 \mathrm{bc}$ \\
\hline N96009C & $\mathrm{NC} 12 \mathrm{C} \times \mathrm{N92063 \textrm {C }}$ & 0.250 & 0.078 & 4 & $19.9 \mathrm{~cd}$ \\
\hline VA 93B & VA $81 B \times$ VA 78039 & 0.432 & 0.064 & 6 & $18.5 \mathrm{de}$ \\
\hline *NC 7 & F393-7-47-1-7-1 × NC 5 & 0.621 & 0.054 & 8 & $17.9 \mathrm{e}$ \\
\hline *N92056C & NC-V11 × NC Ac 18016 & 0.264 & 0.078 & 4 & $17.2 \mathrm{ef}$ \\
\hline N96074L & N90004 × GP-NC WS 13 & 0.100 & 0.092 & 3 & $15.9 \mathrm{f}$ \\
\hline N96076L & N90004 × GP-NC WS 13 & 0.039 & 0.081 & 4 & $15.8 \mathrm{f}$ \\
\hline${ }^{*} \mathrm{GP}-\mathrm{NC}$ WS $12^{\mathrm{z}}$ & NC $6 \times($ NC $3033 \times$ GP-NC WS 1$)$ & $\ldots$ & $\ldots$ & $\ldots$ & $11.5 \mathrm{~g}$ \\
\hline
\end{tabular}

u Values followed by the same letter are not significantly different according to the Waller-Duncan procedure with $\mathrm{K}=100$. Minimum significant difference was 1 to $8 \mathrm{~mm}$.

$\mathrm{v} *$ Selected for isolate-host specificity test.

${ }^{\text {w }}$ Adjusted mean incidence of Sclerotinia blight in field trials conducted from 1996 to 1999.

${ }^{x}$ Number of trials containing the line.

${ }^{y}$ Based on mean lesion length in millimeters 3 days after inoculation on detached leaves with $S$. minor isolate 58.

${ }^{\mathrm{z}}$ Reported as resistant in field trials (14). 
Isolate-host specificity. An analysis of variance was conducted on data combined from the two trials of this experiment. Significant main effects were found for isolates $(P<0.0001)$ and breeding lines or cultivars $(P=0.0133)$. These effects were similar to those found in the previous tests of each factor alone (Tables 1 and 2; Fig. 2). No significant isolate $\times$ entry interaction was found and the ranking of isolates was similar across lines $(P=0.2175$; Fig. 2). For example, isolate 24 was selected for testing isolate-host specificity for its lack of aggressiveness. When tested against five breeding lines differing in their apparent susceptibility, isolate 24 was consistently the least aggressive of the six isolates. Although source effects (greenhouse versus field) were not consistent in the two trials (source $\times$ trial interaction was significant at $P=0.0017)$, GP-NC WS 12 was the most resistant entry regardless of isolate or plant source.

\section{DISCUSSION}

Detached leaflet inoculation was a simple and rapid method for evaluating resistance to $S$. minor in peanut. Escapes were rare with this method and measurement of lesion length yielded consistent results, as evidenced by the lack of trial-trial variation and trial $\times$ treatment interaction in these experiments. The relatively small space and amount of tissue required for inoculation allowed a large number of treatments and replicates to be used in a given experiment.

Several investigators have adopted detached leaf inoculations for evaluating resistance to $S$. sclerotiorum in soybean $(1,13)$ and dry bean $(23)$ and $S$. trifoliorum in alfalfa (20). As in our studies, resistance ratings based on leaf inoculation of soybean with $S$. sclerotiorum were moderately correlated $(r=0.47, P \leq 0.05)$ with field resistance (13). Detached leaf inoculation subsequently was used to identify putative quantitative trait loci for resistance to $S$. sclerotiorum among 500 recombinant inbred lines derived from crosses of a susceptible soybean cultivar with partially resistant cultivars (1). In alfalfa, parental lines and large breeding populations were screened using detached leaf inoculations with S. trifoliorum. Progeny of plants identified as resistant had significantly less disease in field trials than progeny of susceptible or randomly selected lines (20). These examples illustrate the utility of using detached leaf inoculations to screen large populations for resistance to Sclerotinia.

The successful use of this method does not preclude the possibility that other plant parts (stems, pegs, and pods) may respond differently to the pathogen. Detached leaflet inoculation may be a relatively severe test of host resistance. Although the mycelial plugs used as inoculum were small in diameter and cultured on PDA plates of uniform thickness, the small volume of agar in the plug provided a nutrient base for the fungus, and thereby may have enhanced lesion development. Furthermore, leaf tissue probably is more prone to fungal invasion than stems. Infection of leaves is readily observed in the field, but $S$. minor causes its most extensive damage on peanut stems. Therefore, previous methods have focused on stem inoculation $(3,5,15)$.

Isolate 20

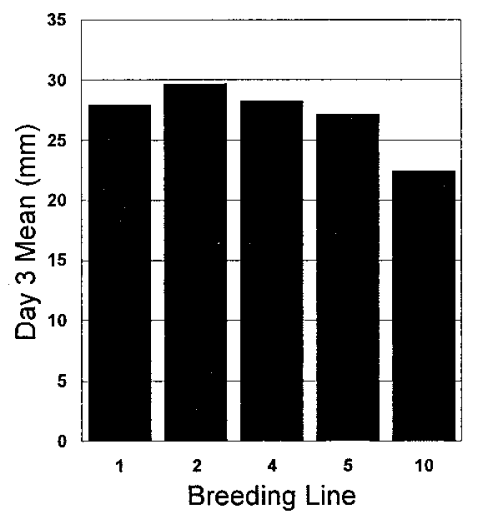

Isolate 58

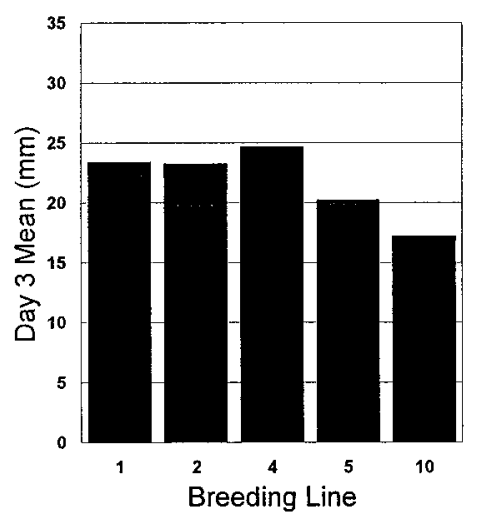

Isolate 42

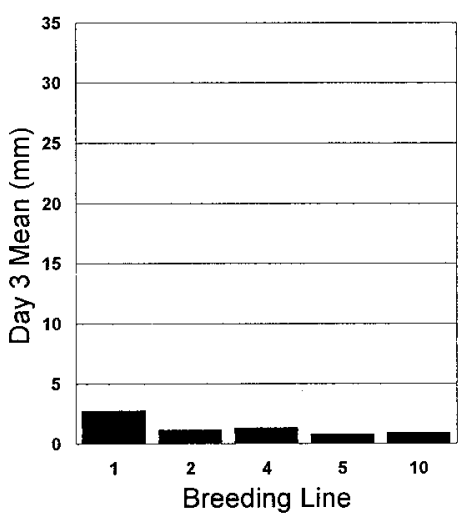

Nevertheless, the levels of resistance found in the peanut lines we tested were not overwhelmed by leaflet inoculation.

In contrast to the results presented here with S. minor, detached leaflet inoculation was less successful in identifying peanut lines with resistance to $R$. solani (8). Differences in the infection and colonization process of the two pathogens could account for differences in the utility of leaflet inoculation.
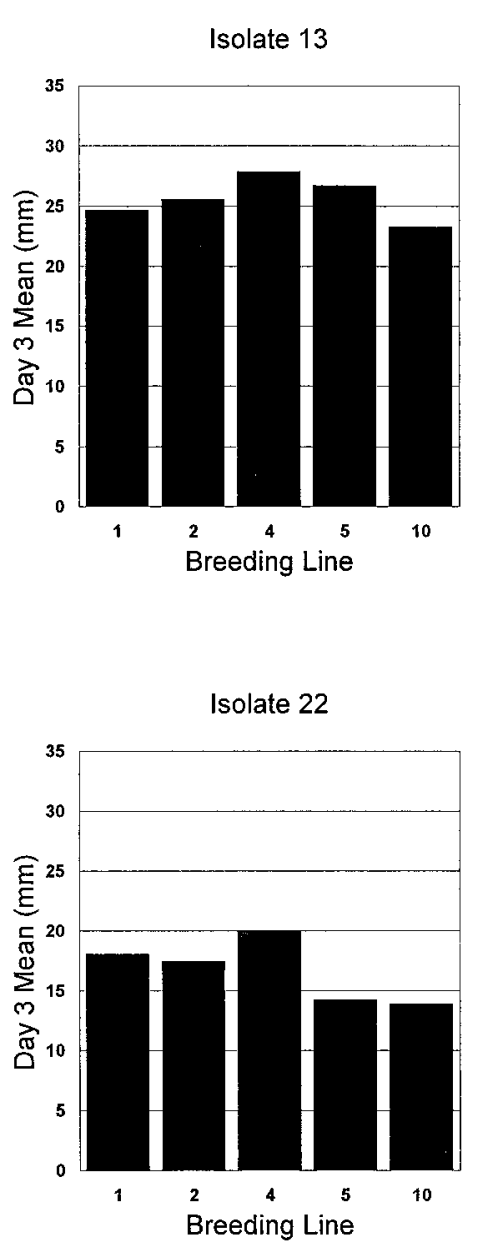

Isolate 24

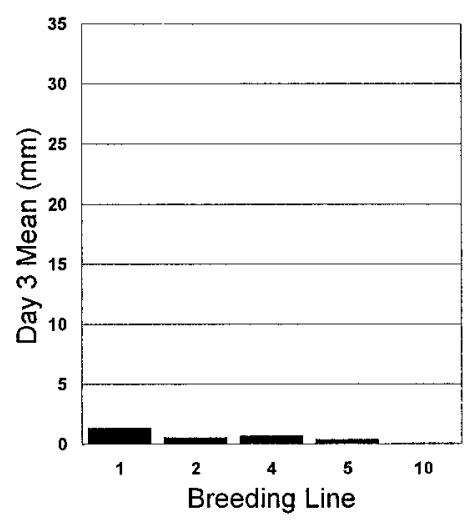

Fig. 2. Mean lesion length of six Sclerotinia minor isolates on five peanut breeding lines or cultivars. Lines are identified as follows: $1=\mathrm{NC} 7,2=\mathrm{N} 91026 \mathrm{E}, 4=$ Perry, $5=\mathrm{N} 92056 \mathrm{C}$, and $10=\mathrm{GP}-\mathrm{NC}$ WS 12. Isolate and peanut line main effects were significant at $P<0.0001$ and $P=0.0133$, respectively. The least significant difference $(P=0.05)$ for comparing breeding lines within isolates is 1.63 . 
Several of the lines identified as resistant in leaflet inoculations, for example N92056C, N96074L, and N96076L, also performed well in field resistance evaluations. Due to limited seed supplies, GP-NC WS 12, which was the most resistant line in these studies, was not tested in our field evaluations. However, it was reported as resistant in earlier field experiments (14). The lines N96074L, N96076L, and GP-NC WS 12 were derived from a cross between $A$. hypogaea and the wild species $A$. cardenasii. Because these lines have complex pedigrees, it is unclear if resistance originated from the wild species ancestor. GP-NC WS 15, another line derived from this cross, did not exhibit resistance to $S$. minor in these experiments. None of these resistant lines is a candidate for release as a commercial cultivar.

Cvs. Perry, VA 93B, and VA 98R are rated as susceptible to moderately resistant to Sclerotinia blight in the field, whereas NC 7 is rated as very susceptible $(2,12,14)$. In the detached leaflet inoculations, NC 7 consistently appeared more resistant than the other cultivars. Similar results were found in stem inoculations (unpublished data). It is likely that some of the differences between field and laboratory performance in these lines are related to contributions of plant architecture to disease development in the field (6).

The population structure of $S$. minor found in the peanut-producing areas of North Carolina and Virginia is currently under study. The degree of genotypic variability among the isolates we collected has not been determined, but the isolates exhibited a wide range of aggressiveness on peanut leaflets. A similar range of aggressiveness among isolates of $S$. minor from annual weed species also has been observed (10). Morphological and cultural differences generally were minimal, except that the least-aggressive isolates also grew slowly on culture media. Interestingly, significant differences in aggressiveness were found among isolates 20,22 , and 24 in four separate experiments (two trials of the aggressiveness test and two trials of the host-isolate test). These isolates were collected from the same farm in August 1998, indicating that large differences in isolate aggressiveness can occur in relatively small geographic areas. Spatially heterogeneous distributions of aggressive and nonaggressive isolates could contribute to experimental variation during field evaluations of resistance. We did not find evidence for isolate specificity on certain host genotypes in the combinations tested here.

The results of these experiments illustrate the utility of detached leaflet inoculations for evaluating resistance to $S$. minor in peanut and for evaluating differences in isolate aggressiveness. Tests with excised tissues are not a substitute for field evaluations of resistance, but could be useful for preliminary screening of large numbers of lines and for confirmation of resistance in advanced breeding lines.

\section{ACKNOWLEDGMENTS}

We thank the Everett Byrd Foundation for funding; and M. Gumpertz, H. Melouk, P. Phipps, and M. Smith for assistance in this project.

\section{LITERATURE CITED}

1. Arahana, V. S., Graef, G. L., Specht, J. E., Steadman, J. R., and Eskridge, K. M. 2001. Identification of QTLs for resistance to Sclerotinia sclerotiorum in soybean. Crop Sci. 41:180-188.

2. Bailey, J. E. 2000. Peanut disease management in 2000. In: 2000 Peanut Information. Coop. Ext. Serv. Ext. Publ. AG-331. North Carolina State University, Raleigh.

3. Brenneman, T. B., Phipps, P. M., and Stipes, R. J. 1988. A rapid method for evaluating genotype resistance, fungicide activity, and isolate pathogenicity of Sclerotinia minor in peanut. Peanut Sci. 15:104-107.

4. Butzler, T. M. 1995. Integrated management of Sclerotinia blight: utilizing canopy morphology, mechanical pruning, and fungicide timing. M.S. thesis, North Carolina State University, Raleigh.

5. Chappell, G. F., II, Shew, B. B., Ferguson, J. M., and Beute, M. K. 1995. Mechanisms of resistance to Sclerotinia minor in selected peanut genotypes. Crop Sci. 35:692-696.

6. Coffelt, T. A., and Porter, D. M. 1982. Screening peanuts for resistance to Sclerotinia blight. Plant Dis. 66:385-387.

7. Coffelt, T. A., Porter, D. M., and Mozingo, R. W. 1994. Registration of 'VA 93B' peanut. Crop Sci. 34:1126.

8. Franke, M. D., and Brenneman, T. B. 2001. Evaluation of detached shoot and leaflet inoculation techniques to screen peanut genotypes for resistance to Rhizoctonia limb rot. Peanut Sci. 28:24-28.
9. Green, S., Bourdot, G. W., and Harvey, I. C. 1995. Limitations of in vitro strain screening methods for the selection of Sclerotinia spp. as potential mycoherbicides against the perennial weed Ranunculus acris. Biocontr. Sci. Technol. 5:147-155.

10. Hollowell, J. E., Shew, B. B., Cubeta, M. A., and Wilcut, J. W. 2003. Weed species as hosts of Sclerotinia minor in peanut fields. Plant Dis. 87:197-199.

11. Hubbard, J. C., Subbarao, K. V., and Koike, S. T. 1997. Development and significance of dicarboximide resistance in Sclerotinia minor isolates from commercial lettuce fields in California. Plant Dis. 81:148-153.

12. Jordan, D. L. 2002. 2002 Peanut Information. Coop. Ext. Serv. Ext. Publ. AG-331. North Carolina State University, Raleigh.

13. Kim, H. S., Hartman, G. L., Manandhar, J. B., Graef, G. L., Steadman, J. R., and Diers, B. W. 2000. Reaction of soybean cultivars to Sclerotinia stem rot in field, greenhouse, and laboratory evaluations. Crop Sci. 40:665-669.

14. Lemay, A. V., Bailey, J. E., and Shew, B. B. 2002. Resistance of peanut to Sclerotinia blight and the effect of acibenzolar- $S$-methyl and fluazinam on disease incidence. Plant Dis. 86:1315-1317.

15. Melouk, H. A., Akem, C. N., and Bowen, C. 1992. A detached shoot technique to evaluate the reaction of peanut genotypes to Sclerotinia minor. Peanut Sci. 19:58-62.

16. Melzer, M. S., and Boland, G. J. 1996. Transmissible hypovirulence in Sclerotinia minor. Can. J. Plant Pathol. 18:19-28.

17. Mozingo, R. W., Coffelt, T. A., and Isleib, T. G. 2000. Registration of 'VA 98R' peanut. Crop Sci. 40:1202-1203.

18. Porter, D. M., and Beute, M. K. 1974. Sclerotinia blight of peanuts. Phytopathology 64:263-264.

19. Porter, D. M., and Melouk, H. A. 1997. Sclerotinia blight. Pages 34-36 in: Compendium of Peanut Diseases. 2nd ed. N. Kokalis-Burelle, D. M. Porter, R. Rodríguez-Kábana, D. H. Smith, and P. Subrahmanyam, eds. American Phytopathological Society Press, St. Paul, MN.

20. Pratt, R. G. 1996. Screening for resistance to Sclerotinia trifoliorum in alfalfa by inoculation of excised leaf tissue. Phytopathology 86:923-928.

21. Riddle, G. E., Burpee, L. L., and Boland, G. J 1991. Virulence of Sclerotinia sclerotiorum and S. minor on dandelion (Taraxacum officinale). Weed Sci. 39:109-118.

22. Simpson, C. E., Smith, O. D., and Melouk, H. A. 2000. Registration of 'Tamrun 98' peanut. Crop Sci. 40:859.

23. Steadman, J. R., Powers, K., and Higgins, B. 1997. Screening common bean for white mold resistance using detached leaves. Annu. Rep. Bean Improv. Coop. 40:140-141. 